\title{
Ongoing Challenges in Pharmacovigilance
}

\author{
Gerald J. Dal Pan
}

Published online: 22 November 2013

(C) Springer International Publishing Switzerland (outside the USA) 2013

\begin{abstract}
While pharmacovigilance systems have made substantial progress in the past several decades, all pharmacovigilance systems face a common set of ongoing challenges in drug safety surveillance in five principal interrelated areas: engaging the public, collaboration and partnerships, incorporating informatics, adopting a global approach, and assessing the impact of efforts. In broad terms, these challenges are not new. Rather, advances in science and technology, along with more demanding societal expectations, have changed the nature of these challenges and provided new opportunities to move the field forward. Differences in organization and levels of development, as well as regional differences, necessarily imply that a single approach is not suitable for all regions, though sharing of best practices can help each region.
\end{abstract}

\section{Introduction}

Pharmacovigilance is "the science and activities relating to the detection, assessment, understanding and prevention of adverse effects or any other drug-related problem" [1]. The field's remit is broad, though its origins are in drug safety surveillance to monitor the adverse effects of medicines [2]. Today, the scope of drug safety surveillance is expansive and is becoming increasingly complex because the safety of a medicine is related not only to its pharmacological properties but also to how it is used in actual practice and to the integrity of the product's quality throughout the supply chain [3]. While medication errors and product quality concerns have always been important

G. J. Dal Pan $(\bowtie)$

US Food and Drug Administration, 10903 New Hampshire Ave., Building 22, Room 4304, Silver Spring, MD, USA

e-mail: gerald.dalpan@fda.hhs.gov aspects of drug safety surveillance, their integration into pharmacovigilance systems has increased in recent years.

The nature of pharmacovigilance systems varies around the world. In many countries, regional pharmacovigilance centres, many of which are based in hospitals or universities, collect and analyze adverse drug reaction reports and forward those reports to national centres of pharmacovigilance. By contrast, in the USA, practitioners and patients report adverse events to pharmaceutical manufacturers (who, in turn, have regulatory obligations to send certain reports to the US Food and Drug Administration [FDA]) and, to a much lesser extent, directly to the US FDA. Some national centres are within a drug regulatory agency, while others collaborate with the drug regulatory agency. Pharmaceutical manufacturers generally have reporting requirements within these systems. In nascent and emerging pharmacovigilance systems, the relative roles of hospitals, universities, regulatory agencies and industry may differ from those in more developed systems. In countries with highly developed regulatory systems, the pharmaceutical industry plays a major role in pharmacovigilance.

Despite differences in organization and levels of development, all pharmacovigilance systems face common challenges in drug safety surveillance; to address these challenges, they must embrace new opportunities in five principal interrelated areas: engaging the public, collaboration and partnerships, incorporating informatics, adopting a global approach, and assessing the impact of efforts. In broad terms, these challenges are not new. Rather, advances in science and technology, along with more demanding societal expectations, have changed the nature of these challenges and the field's approach to them. Regional differences necessarily imply that a single approach is not suitable for all regions, though sharing of best practices can help each region. 


\section{Engaging the Public}

Pharmacovigilance is, first and foremost, about and for patients and the practitioners who care for them. As drug safety surveillance systems move into the future, they must continue to listen to patients and practitioners and to provide them with useful and actionable information about the safety and safe use of medicines. The best ways to do this are not yet known.

Identifying previously unknown adverse effects of medicines remains a central concern of pharmacovigilance. For decades, the foundation of drug safety surveillance has been reporting of suspected adverse drug reactions from patients and practitioners. The logic behind these so-called spontaneous reports is that careful observation and clinical reasoning at the point of care raise suspicion of an adverse drug reaction. Review of well documented reports can provide sufficient evidence that a drug is indeed responsible for an adverse reaction; appropriate action, usually in the form of a warning on the drug's label, can be taken on this basis. Examples of adverse drug reactions identified by spontaneous reports include-to name a few-aplastic anaemia with felbamate [4], liver toxicity with troglitazone [5], rhabdomyolysis with cerivastatin [6] and, more recently, progressive multifocal leukoencephalopathy with natalizumab [7] and efalizumab [8]. Drug safety surveillance systems based on spontaneous reports remain essential components of modern drug regulatory systems; for example, in both France and the USA, a substantial proportion of safety-related regulatory actions are based on spontaneous reports $[9,10]$.

While the total number of adverse event reports has increased steadily over the past several decades [11, 12], reporting of adverse drug reactions and suspected adverse drug reactions has always been low [13-15]. For this reason, it is essential that pharmacovigilance systems continue to engage patients and practitioners to report suspected adverse drug reactions. While the value of reports from patients remains to be clarified [16], patient-generated reports can complement those generated by healthcare professionals [17, 18], by focusing on health status. Because patients may not fully appreciate the association of a medication with an adverse experience, may not feel obligated or may not be motivated to report the adverse event [19], they should be encouraged to report new symptoms to their physician and prompt practitioners to report suspected adverse drug reactions. Further research in this area is needed.

Similarly, pharmacovigilance systems must continue to engage practitioners to submit high-quality reports of suspected adverse drug reactions. For pharmacovigilance systems that are already generating and transmitting large numbers of reports, current efforts must focus on report quality. In these systems, increasing the number of reports that provide little to no useful information will burden pharmacovigilance centres and divert resources from other important activities. On the other hand, for nascent and emerging pharmacovigilance systems, there is a clear need to increase the number of reports and, at the same time, monitor the quality and utility of these reports.

To support more involvement of health professionals in pharmacovigilance, their education would ideally include instruction on recognition of drug-induced disease and adverse drug reactions, on the need to be engaged with pharmacovigilance systems and on the characteristics of a high-quality, though concise, case report. Surveys from around the world document that while patient safety is being introduced into medical curricula, the amount of time given to the topic is likely insufficient [20-24]. Targeted interventions have also been used to improve reporting among practitioners. For example, a study in a tertiary-care teaching hospital in Spain found that a combination of educational efforts and financial incentives resulted in an increase in the number of reports of adverse drug reactions and in the proportion of reports of serious adverse drug reactions [25]. Importantly, there was an increase in the number of previously unknown or poorly known suspected adverse drug reactions after the introduction of these interventions. More evidence-based approaches to increasing practitioner engagement are needed. Beyond engaging practitioners individually, practitioners can be engaged collectively. For example, a partnership between a pharmacovigilance centre and a consortium of practitioners who care for patients with a certain rare disease can be developed to enhance adverse event reporting in this setting, which otherwise might be inadequately addressed [26]. Similarly, partnerships with consortia of practitioners who specialize in certain types of adverse drug reactions, such as drug-induced liver injury, can provide both detailed adverse event reports and interactions with clinical specialists [27].

Pharmacovigilance systems must also provide patients and practitioners with useful, actionable information about medicines. As a start, it is important to understand stakeholders' needs. For example, a study of the drug information needs of Nigerian pharmacists [28] found that they sought information most frequently to learn about adverse drug reactions and to counsel patients. The study found that tertiary sources of drug information were used most commonly. The study authors noted that tertiary sources quickly become outdated, and they called for better access to current sources of drug information. The availability of current information, however, does not guarantee its utility or acceptance. Recent studies, for example, have demonstrated that information for patients is often not useful [29, 30] and that patients often do not have adequate 
understanding of patient-directed prescription drug information [31-33]. Similarly, studies have shown that practitioners may not adequately or appropriately act upon warnings from drug regulators [34]. Pharmacovigilance systems, and the regulatory agencies that work with them, must redouble their efforts to strengthen bidirectional communication with their most important stakeholders, patients and healthcare practitioners. Perhaps more than the technical and scientific aspects of the pharmacovigilance, the nature of these interactions will vary from country to country and will depend on local needs, the structure of the healthcare system and other factors.

\section{Collaboration and Partnerships}

Pharmacovigilance is a collaborative endeavour. Because of its broad scope, pharmacovigilance systems cannot function in isolation from other public health agencies. Rather, pharmacovigilance systems must form partnerships that provide complementary expertise and a capacity to accomplish comprehensive monitoring and investigations of the safety of medicines. Increasingly, pharmacovigilance systems are addressing issues related to product quality; substandard, spurious, falsely labelled, falsified and counterfeit medical products [35]; and medication errors [36]. While pharmacovigilance systems historically have addressed these issues [37], many pharmacovigilance systems are typically not equipped to identify all such problems, in part because adverse outcomes are not initially recognized as being related to medicines at the point of care. Rather, other public health systems may be called in to investigate a health-related problem and may subsequently identify it as being related to medicines. For example, it was discovered that clusters of hypotension and allergic-type symptoms in patients undergoing dialysis treatment in the USA were related to a particular manufacturer's brand of heparin only after a thorough outbreak investigation by state and local health authorities and the US Centers for Disease Control and Prevention [38]. The US FDA began working with these agencies, and the clinical syndrome was further characterized and a contaminant was identified [39]. Spontaneous adverse event reports were received only after publicity about the outbreak, and such stimulated reporting made interpretation of the reports difficult [40]. Similarly, fungal contamination of compounded methylprednisolone used for epidural injection led to an outbreak of fungal meningitis in the USA, which was identified and characterized by state and local health departments [41]. Each of these outbreaks required real-time, patient-level investigation at the point of care-an activity for which traditional pharmacovigilance units are not typically staffed. Thus, partnerships with public health agencies (including poison control centres) with specialized expertise are essential. Furthermore, in these situations, pharmacovigilance units must adapt to working in real time to meet the urgent public health needs of an outbreak.

Certain drug administration programmes, such as mass drug administration programmes for endemic illnesses [42, 43] or drug administration programmes during an epidemic [44], also require collaboration between pharmacovigilance centres and other public health authorities to ensure that timely, adequate information on adverse events is collected in a way that does not impede access to necessary medication. Especially in resource-limited settings, pharmacovigilance activities are often not incorporated into drug administration programmes, such as those for malaria [45] and HIV infection [46]. Development of partnerships that bring together the necessary expertise will be a first step toward incorporation of drug safety surveillance into drug administration programmes; other barriers, such as funding, will also need to be overcome.

Partnerships and collaboration among pharmacovigilance centres are also important for sharing of information, development of best practices in pharmacovigilance and strengthening the science of pharmacovigilance. The World Health Organization (WHO) Programme for International Drug Monitoring and its collaborating centre, the Uppsala Monitoring Centre, provide a forum for these activities for the national centres of pharmacovigilance of the 117 member countries [47]. Through training efforts and the interactions among members, these efforts have been critical in building pharmacovigilance systems around the world. Further collaborative efforts, such as regional efforts, should build upon the framework that the WHO and the Uppsala Monitoring Centre have established.

\section{Incorporation of Informatics}

Pharmacovigilance relies on good information. Advances in the availability of data and analytic methods are changing the landscape of pharmacovigilance and can expand the field's scope and reach. For example, advances in informatics can be used to perform data mining in large spontaneous-reporting databases [48], review large numbers of reports with advanced techniques such as natural language processing [49], develop active surveillance systems, allow new sources of data to be used for identifying drug safety signals, and facilitate reporting of suspected adverse drug reactions.

As healthcare data systems have moved from paperbased medical records to electronic healthcare records, there has been growing interest in mining these data to identify drug safety signals [50]. Similarly, there has been 
interest in mining internet-based data [51] to identify side effects of medicines. The feasibility of generating individual case safety reports from electronic medical records has been demonstrated [52], though the utility of automated individual case safety reports is limited if sufficient relevant clinical details are not included [53]. Discussions within an internet-based, disease-specific patient forum have generated information on suspected adverse drug reactions, including those associated with off-label use [54]. Researchers have used logs of internet search terms to identify patterns that may suggest a specific drug-drug interaction [55]. In each of these cases, the lack of clinical details and the inability to obtain needed details are important limitations. A critical challenge for pharmacovigilance is to develop and validate methods that maximize the utility of the large number of electronic data available from a variety of sources and minimize false positive findings (which carry the cost of evaluation of each signal and the potential to divert patients from an acceptable therapy). It will be essential to integrate informatic approaches with other sources of information and with clinical reasoning.

Two major limitations in currently available pharmacovigilance data are the minimal data on indications for use [56], both in spontaneous reports and in large healthcare databases, and the minimal data on product identifiers, such as manufacturer details and lot numbers. A cross-sectional study of the traceability of biopharmaceuticals in both the US FDA's Adverse Event Reporting System (FAERS) and in the EudraVigilance database found that in each database, batch numbers are reported infrequently for biopharmaceuticals (24.0 and $21.1 \%$, respectively) and even less frequently for small-molecule medicines (7.4 and $3.6 \%$, respectively) [57]. The widespread use of generic medicines and the advent of biosimilar products underscore the need for proper product identification in pharmacovigilance. Uniform data on product identification would allow for better correlation of adverse event data with product quality data and would be an important advance in bridging the gap between pharmacovigilance systems and product quality systems.

Large, population-based healthcare databases have been used for decades to conduct observational epidemiological drug safety studies [58]. These studies have traditionally relied on careful protocol development, identification of an appropriate database and statistical programming customized on a study-by-study basis to match the protocol with the characteristics of the chosen database. This process is appropriate and necessary to yield high-quality results but is not flexible for rapid exploration, on a population-based level, of an emerging drug safety signal. Aggregated data from large, population-based databases using a common data model allow for rapid processing of prespecified queries, which can provide population-based rates of adverse drug reactions and thus provide important context around drug safety signals that arise from spontaneous reports whose significance is not clear [59]. For example, the Mini-Sentinel system [60] aggregates data by using a distributed database model (rather than a centralized database model) to estimate population-based rates of adverse drug reactions. The US FDA used this system to better understand the large number of spontaneous reports of haemorrhage it received after the introduction of dabigatran, a new oral anticoagulant. The number of reports far exceeded those for warfarin, though clinical trials had demonstrated that the bleeding rates with dabigatran were not higher than those for warfarin. Because of likely stimulated reporting of dabigatran cases, a comparison of reporting rates between dabigatran and warfarin would likely yield a biased estimate of the relative risk of bleeding between the two agents. Using population-based data, which presumably do not suffer from this type of reporting bias, the Mini-Sentinel system clarified that the incidence of gastrointestinal and intracerebral haemorrhage in patients treated with dabigatran was not higher than the corresponding incidence in warfarin-treated patients [61].

There are many efforts to aggregate drug safety data for the purposes of signal detection and signal evaluation. For example, in addition to the Mini-Sentinel system, the EUADR database aggregates population-based data from various European countries [62]. Databases from general practices are used in the UK for drug safety research [63]. The Observational Medical Outcomes Partnership has focused on methodological aspects of using populationbased healthcare data to identify adverse drug reactions [64]. Spontaneous reports of suspected adverse drug reactions reported throughout Europe are aggregated in EudraVigilance [65], while those reported around the world are aggregated in the WHO Global Individual Case Safety Report database, VigiBase ${ }^{\mathrm{TM}}$ [66]. While all of these efforts are focused on drug safety assessments, each uses a different approach. The advantages of multiple approaches in multiple databases will be realized only if researchers compare their results to identify factors-whether related to data or to methodology - that impact the performance of these systems. Such efforts are already underway [67, 68]. While the transmission of spontaneous reports to and between large databases is largely via standards set forth by the International Conference on Harmonization, there is currently no standardized common data model for large, population-based databases used for drug safety assessments.

Finally, technological advances can facilitate bidirectional communication between pharmacovigilance centres and patients and practitioners, especially in areas where no other infrastructure exists. For example, toll-free mobile 
phone calls were used to quantify exposure to anti-malarial drugs obtained from the private retail sector in Sagamu, Nigeria, and to monitor adverse effects associated with the use of these medicines [69]. Similarly, structured interviews using mobile phone technology were used to conduct a cohort study examining the safety of the H1N1 vaccine in children in Saudi Arabia [70]. Mobile technologies can also be used to disseminate health information, though more work is likely needed to optimize the use of this technology [71].

\section{Adopting a Global Approach}

Pharmacovigilance is a global endeavour. With the increasing use and movement of medicines around the world, the importance of a global approach to drug safety is more important now than ever. While many hurdles must be overcome before this goal is reached, the primary challenge that must be addressed is development of the infrastructure and capacity for feasible and meaningful pharmacovigilance systems in the many low- and middleincome countries that do not yet have fully functional drug regulatory systems. A questionnaire-based survey of 55 low- and middle-income countries identified many gaps in infrastructure and resources for pharmacovigilance [72]. An analysis of reporting over a 10-year period to VigiBase $^{\mathrm{TM}}$ found that high-income countries had higher rates of reporting than did low-income countries [73]. Importantly, though perhaps not surprisingly, this analysis also found a difference in the drugs for which reports were submitted, based on country income. High-income countries submitted more reports for antineoplastic and immunomodulatory drugs, while low-income countries submitted more reports for systemic anti-infective agentsan observation that underscores the need for national and regional pharmacovigilance systems to be designed with their relevant public health needs in mind. The case of reporting suspected adverse drug reactions for anti-malarial agents illustrates this need. An analysis of global reporting of suspected adverse drug reactions associated with the use of anti-malarial agents (including artemisinin-based combination therapy) to the WHO Programme for International Drug Monitoring found that only $1.2 \%$ of reports came from low-income countries where malaria is endemic (Priority 1 countries) [74]. The authors noted that only $2 \%$ of reports came from countries in sub-Saharan Africa-an area that accounts for $86 \%$ of malaria cases and $91 \%$ of malaria-related deaths. Priority 3 countries (high-income countries regardless of malaria control status and malariafree countries regardless of income) accounted for $84 \%$ of reports. It is precisely mismatches and gaps of this type, whose potential negative public health consequences are substantial, that must be overcome. Funding, governance, goals, expectations, accountability, technical capacityand, where relevant, linkage to drug administration programmes-are some of the practical issues that must be worked out.

One component of a global approach is harmonization, the process of establishing common technical standards across countries and regions that have diverse legal and regulatory bases for drug regulation. Efforts of the International Conference on Harmonisation of Technical Requirements for Registration of Pharmaceuticals for Human Use (ICH) began in 1990 and focused on interactions between pharmaceutical companies and drug regulatory authorities in three regions: the USA, Europe and Japan. As efforts at harmonization go beyond the three ICH regions and include countries whose drug regulatory and pharmacovigilance systems are at different stages of development, it will be important that harmonization processes take into account these differences. Furthermore, as laws are enacted around the world that set forth detailed pharmacovigilance requirements for pharmaceutical companies in individual countries, it may be difficult to achieve harmonization. For post-approval drug safety initiatives that require interaction of the manufacturer with the healthcare system, such as specific risk management initiatives, full harmonization may be impossible because of differences in healthcare delivery across countries.

\section{Assessing Impact}

Pharmacovigilance requires resources and is expected to protect and improve public health. While there have been substantial advances in pharmacovigilance activities around the world in the past decade, relatively little attention has been paid to the impact and burden of these efforts. As national, regional and international databases of suspected adverse drug reactions grow in size-and, in some cases, in scope - the demand for data analyses (both by humans and by computers) to quickly identify important adverse drugs reactions and to refute unsubstantiated signals grows proportionately. These efforts require people, time and money-resources that are not increasing in proportion to the explosion of the available data. The impact of these efforts toward improving human health has not been systematically examined. A recent paper attempted to quantify the cost-effectiveness of the Period Safety Update Report (PSUR) in Europe [75]. Using methods that have been previously used to assess medical interventions, the authors concluded that the incremental cost-effectiveness ratio of requiring PSURs, compared with not requiring PSURs, was $€ 342,110$ per quality-adjusted life-year gained - an amount they claim is above that used 
for reimbursement decisions in Europe. While this type of analysis needs replication and validation, this paper represents an important step in the difficult, yet necessary, task of quantifying the impact and cost of specific pharmacovigilance efforts. Further studies on the impact of a range of pharmacovigilance activities can help pharmacovigilance centres with effective programme planning and resource allocation.

\section{Conclusion}

To meet the multifaceted challenges of pharmacovigilance, a science-based, public-health focused, collaborative and global approach is needed. Evidence-based approaches to engage patients and practitioners in pharmacovigilance need to be developed and tested. Collaboration of pharmacovigilance centres with other public health agencies will allow pharmacovigilance systems to more fully assess the adverse effects of medicines, while collaboration between pharmacovigilance systems will allow sharing of best practices. The increasing availability of informatic systems holds much promise for pharmacovigilancethough, in some cases, a lack of relevant clinical or product details limits the utility of data systems. Global approaches should focus on strengthening pharmacovigilance systems in countries where such systems do not yet exist, and in promoting harmonization. Finally, as pharmacovigilance systems grow, it is important to assess their impact on improving health outcomes.

Acknowledgments The views expressed herein are those of the author and not necessarily those of the US Food and Drug Administration or the US Government. No sources of funding were used to assist in the preparation of this manuscript. Gerald J. Dal Pan has no conflicts of interest that are directly relevant to the content of this article.

\section{References}

1. World Health Organization. The importance of pharmacovigilance. Safety monitoring of medicinal product. Geneva; 2002.

2. Moore N, Paux G, Begaud B, Biour M, Loupi E, Boismare F, Royer RJ. Adverse drug reaction monitoring: doing it the French way. Lancet. 1985;2(8463):1056-8.

3. US Food and Drug Administration. Managing the risks from medical product use. Creating a risk management framework. Rockville, MD; 1999.

4. Nightingale S. Recommendation to immediately withdraw patients from treatment with felbamate. JAMA. 1994;272:995.

5. Kohlroser J, Mathai J, Reichheld J, Banner BF, Bonkovsky HL. Hepatotoxicity due to troglitazone: report of two cases and review of adverse events reported to the United States Food and Drug Administration. Am J Gastroenterol. 2000;95:272-6.

6. Staffa JA, Chang J, Green L. Cerivastatin and reports of fatal rhabdomyolysis. N Engl J Med. 2002;346:539-40.

7. Kleinschmidt-DeMasters BK, Tyler KL. Progressive multifocal leukoencephalopathy complicating treatment with natalizumab and interferon beta-1a for multiple sclerosis. $\mathrm{N}$ Engl $\mathrm{J}$ Med. 2005;353:369-74.

8. Kothary N, Diak IL, Brinker A, Bezabeh S, Avigan M, Dal Pan G. Progressive multifocal leukoencephalopathy associated with Efalizumab use in psoriasis patients. J Am Acad Dermatol. 2011;65:546-51.

9. Paludetto MN, Olivier-Abbal P, Montastruc JL. Is spontaneous reporting always the most important information supporting drug withdrawals for pharmacovigilance reasons in France? Pharmacoepidemiol Drug Saf. 2012;21:1289-94.

10. Lester J, Neyarapally GA, Lipowski E, Graham CF, Hall M, Dal Pan G. Evaluation of FDA safety-related drug label changes in 2010. Pharmacoepidemiol Drug Saf. 2013;22:302-5.

11. Meyboom RHB, Lindquist M, Egberts ACG, Edwards IR. Signal selection and follow-up in pharmacovigilance. Drug Saf. 2002;6:459-65.

12. Woodcock J, Behrman RE, Dal Pan GJ. Role of postmarketing surveillance in contemporary medicine. Annu Rev Med. 2011;62:1-10.

13. Rogers A, Israel E, Smith $\mathrm{C}$, et al. Physician knowledge, attitudes, and behavior related to reporting adverse drug events. Arch Int Med. 1988;148:1596-600.

14. Scott H, Rosenbaum S, Waters W, et al. Rhode Island physicians' recognition and reporting of adverse drug events. R I Med J. 1987;70:311-6.

15. McAdams M, Staffa J, Dal Pan G. Estimating the extent of reporting to FDA: a case study of statin-associated rhabdomyolysis. Pharmacoepidemiol Drug Saf. 2008;17:229-39.

16. Aagaard L, Hansen EH. Adverse drug reactions reported by consumers for nervous system medications in Europe 2007 to 2011. BMC Pharmacol Toxicol. 2013;14:30. doi:10.1186/20506511-14-30.

17. Hazell L, Cornelius V, Hannaford P, Shakir S, Avery AJ, Yellow Card Study Collaboration. How do patients contribute to signal detection? A retrospective analysis of spontaneous reporting of adverse drug reactions in the UK's Yellow Card Scheme. Drug Saf. 2013;36:199-206.

18. Basch E, Jia X, Heller G, Barz A, Sit L, Fruscione M, Appawu M, Iasonos A, Atkinson T, Goldfarb S, Culkin A, Kris MG, Schrag D. Adverse symptom event reporting by patients vs clinicians: relationships with clinical outcomes. J Natl Cancer Inst. 2009;101:1624-32.

19. Lortmer S, Cox A, Langford NJ. A patient's perspective: the impact of adverse drug reactions on patients and their views on reporting. J Clin Pharm Ther. 2012;37:148-52.

20. Nundy S. Adverse events: learning the science behind the art. Acad Med. 2008;83:1164.

21. Alper E, Rosenberg EI, O’Brien KE, Fischer M, Durning SJ. Patient safety education at U.S. and Canadian medical schools: results from the 2006 Clerkship Directors in Internal Medicine survey. Acad Med. 2009;84:1672-6.

22. Gwee MC. Teaching of medical pharmacology: the need to nurture the early development of desired attitudes for safe and rational drug prescribing. Med Teach. 2009;31:847-54.

23. Maeda S, Kamishiraki E, Starkey J. Patient safety education at Japanese medical schools: results of a nationwide survey. BMC Res Notes. 2012;10:226.

24. Nie Y, Li L, Duan Y, Chen P, Barraclough BH, Zhang M, Li J. Patient safety education for undergraduate medical students: a systematic review. BMC Med Educ. 2011;14(11):33.

25. Pedrós C, Vallano A, Cereza G, Mendoza-Aran G, Agustí A, Aguilera C, Danés I, Vidal X, Arnau JM. An intervention to improve spontaneous adverse drug reaction reporting by hospital physicians: a time series analysis in Spain. Drug Saf. 2009;32:77-83.

26. Lionetti G, Kimura Y, Schanberg LE, Beukelman T, Wallace CA, Ilowite NT, Winsor J, Fox K, Natter M, Sundy JS, Brodsky E, 
Curtis JR, Del Gaizo V, Iyasu S, Jahreis A, Meeker-O'Connell A, Mittleman BB, Murphy BM, Peterson ED, Raymond SC, Setoguchi S, Siegel JN, Sobel RE, Solomon D, Southwood TR, Vesely R, White PH, Wulffraat NM, Sandborg CI et al. Using registries to identify adverse events in rheumatic diseases. Pediatrics. 2013;132:e1384-94.

27. Fontana RJ, Watkins PB, Bonkovsky HL, Chalasani N, Davern T, Serrano J, Rochon J; for the DILIN Study Group. Drug-Induced Liver Injury Network (DILIN) prospective study: rationale, design and conduct. Drug Saf. 2009;32:55-68.

28. Udezi WA, Oparah AC, Enyi KU. An investigation of drug information needs of Nigerian pharmacists. Drug Inf J. 2007:41:471-9.

29. Svarstad BL, Mount JK, Tabak ER. Expert and consumer evaluation of patient medication leaflets provided in US pharmacies. J Am Pharm Assoc. 2005;45:443-51.

30. Winterstein AG, Linden S, Lee AE, Fernandez EM, Kimberlin CL. Evaluation of consumer medication information dispensed in retail pharmacies. Arch Intern Med. 2010;170:1317-24.

31. Enger C, Younus M, Petronis KR, Mo J, Gately R, Seeger JD. The effectiveness of varenicline medication guide for conveying safety information to patients: a REMS assessment survey. Pharmacoepidemiol Drug Saf. 2013;22:705-15.

32. Wolf MS, Davis TC, Shrank WH, Neuberger M, Parker RM. A critical review of FDA-approved medication guides. Patient Educ Couns. 2006;62:316-22.

33. Wolf MS, King J, Wilson EA, Curtis LM, Bailey SC, Duhig J, Russell A, Bergeron A, Daly A, Parker RM, Davis TC, Shrank WH, Lambert B. Usability of FDA-approved medication guides. J Gen Intern Med. 2012;27:1714-20.

34. Dusetzina SB, Higashi AS, Dorsey ER, Conti R, Huskamp HA, Zhu S, Garfield CF, Alexander GC. Impact of FDA drug risk communications on health care utilization and health behaviors: a systematic review. Med Care. 2012;50:466-78.

35. Gostin LO, Buckley GK, Kelley PW. Stemming the global trade in falsified and substandard medicines. JAMA. 2013;309: 1693-4.

36. Bencheikh RS, Benabdallah G. Medication errors: pharmacovigilance centres in detection and prevention. Br J Clin Pharmacol. 2009;67:687-90.

37. Aagaard L, Meyer U, Schaefer M, Hansen EH. Pharmaceutical production problems detected by adverse drug reactions reports: a documentary study from the German Democratic Republic, 1982-1990. J Clinic Toxicol. 2012;2:120.

38. Blossom DB, Kallen AJ, Patel PR, Elward A, Robinson L, Gao G, Langer R, Perkins KM, Jaeger JL, Kurkjian KM, Jones M, Schillie SF, Shehab N, Ketterer D, Venkataraman G, Kishimoto TK, Shriver Z, McMahon AW, Austen KF, Kozlowski S, Srinivasan A, Turabelidze G, Gould CV, Arduino MJ, Sasisekharan R. Outbreak of adverse reactions associated with contaminated heparin. N Engl J Med. 2008;359:2674-84.

39. Kishimoto TK, Viswanathan K, Ganguly T, Elankumaran S, Smith S, Pelzer K et al. Contaminated heparin associated with adverse clinical events and activation of the contact system. N Engl J Med. 2008;358:2457-67.

40. McMahon AW, Pratt RG, Hammad TA, Kozlowski S, Zhou E, Lu S, Kulick CG, Mallick T, Dal Pan G. Description of hypersensitivity adverse events following administration of heparin that was potentially contaminated with oversulfated chondroitin sulfate in early 2008. Pharmacoepidemiol Drug Saf. 2010;19:921-33.

41. Kainer MA, Reagan DR, Nguyen DB, Wiese AD, Wise ME, Ward J, Park BJ, Kanago ML, Baumblatt J, Schaefer MK, Berger BE, Marder EP, Min JY, Dunn JR, Smith RM, Dreyzehner J, Jones TF, Tennessee Fungal Meningitis Investigation Team. Fungal infections associated with contaminated methylprednisolone in Tennessee. N Engl J Med. 2012;367:2194-203.
42. Mehta U, Durrheim D, Mabuza A, Blumberg L, Allen E, Barnes KI. Malaria pharmacovigilance in Africa: lessons from a pilot project in Mpumalanga Province, South Africa. Drug Saf. 2007;30:899-910.

43. de Sousa A, Rabarijaona LP, Tenkorang O, Inkoom E, Ravelomanantena HV, Njarasoa S, Whang JN, Ndiaye JL, Ndiaye Y, Ndiaye M, Sow D, Akadiri G, Hassan J, Dicko A, Sagara I, Kubalalika P, Mathanga D, Bizuneh K, Randriasamimanana JR, Recht J, Bjelic I, Dodoo A. Pharmacovigilance of malaria intermittent preventive treatment in infants coupled with routine immunizations in 6 African countries. J Infect Dis. 2012;205(Suppl 1):S82-90.

44. Sorbello A, Jones SC, Carter W, Struble K, Boucher R, Truffa M, Birnkrant D, Gada N, Camilli S, Chan I, Dallas S, Scales T, Kosko R, Thompson E, Goodman J, Francis H, Dal Pan G. Emergency use authorization for intravenous peramivir: evaluation of safety in the treatment of hospitalized patients infected with 2009 H1N1 influenza A virus. Clin Infect Dis. 2012;55:1-7.

45. Stergachis A, Bartlein RJ, Dodoo A, Nwokike J, Kachur SP. A situational analysis of pharmacovigilance plans in the Global Fund Malaria and US President's Malaria Initiative proposals. Malar J. 2010;9:148.

46. Bakare N, Edwards IR, Stergachis A, Pal S, Holmes CB, Lindquist M, Duncombe C, Dodoo A, Novendstern J, Nwokike J, Kuchenbecker R, Aberg JA, Miller V, Strobos J. Global pharmacovigilance for antiretroviral drugs: overcoming contrasting priorities. PLoS Med. 2011;8(7):e1001054. doi:10.1371/journal. pmed.1001054 (Epub 2011 Jul 5).

47. Uppsala Monitoring Centre. Introduction to the WHO Programme for International Drug Monitoring. http://www.whoumc.org/DynPage.aspx $?$ id $=98080 \& \mathrm{mn} 1=7347 \& \mathrm{mn} 2=7252 \& \mathrm{mn} 3=$ 7322\&mn4=7324. Accessed 11 Nov 2013.

48. Almenoff J, Tonning JM, Gould AL, Szarfman A, Hauben M, Ouellet-Hellstrom R, Ball R, Hornbuckle K, Walsh L, Yee C, Sacks ST, Yuen N, Patadia V, Blum M, Johnston M, Gerrits C, Seifert H, Lacroix K. Perspectives on the use of data mining in pharmacovigilance. Drug Saf. 2005;28:981-1007.

49. Warrer P, Hansen EH, Juhl-Jensen L, Aagaard L. Using textmining techniques in electronic health patient records to identify ADRs from medicine use. Br J Clin Pharmacol. 2011;75:674-84.

50. LePendu P, Iyer SV, Bauer-Mehren A, Harpaz R, Mortensen JM, Podchiyska T et al. Pharmacovigilance using clinical notes. Clin Pharmacol Ther. 2013;93:547-55.

51. Kuehn BM. Scientists mine web search data to identify epidemics and adverse events. JAMA. 2013;209:1883-4.

52. Linder JA, Haas JS, Iyer A, Labuzetta MA, Ibara M, Celeste M, Getty G, Bates DW. Secondary use of electronic health record data: spontaneous triggered adverse drug event reporting. Pharmacoepidemiol Drug Saf. 2010;19:1211-5.

53. Brajovic S, Piazza-Hepp T, Swartz L, Dal Pan G. Quality assessment of spontaneous triggered adverse event reports received by the Food and Drug Administration. Pharmacoepidemiol Drug Saf. 2012;21:565-70.

54. Frost J, Okun S, Vaughan T, Heywood J, Wicks P. Patient-reported outcomes as a source of evidence in off-label prescribing: analysis of data from PatientsLikeMe. J Med Internet Res. 2011;13:e6.

55. White RW, Tatonetti NP, Shah NH, Altman RB, Horvitz E. Webscale pharmacovigilance: listening to signals from the crowd. J Am Med Inform Assoc. 2013;20:404-8.

56. Dal Pan GJ. Monitoring the safety of medicines used off-label. Clin Pharmacol Ther. 2012;91:787-95.

57. Vermeer NS, Straus SM, Mantel-Teeuwise AK, Domergue F, Egberts TC, Leufkens HG et al. Traceability of biopharmaceuticals in spontaneous reporting systems: a cross-sectional study in FDA Adverse Event Reporting System (FAERS) and EudraVigilance databases. Drug Saf. 2013;36:617-25. 
58. Schneeweiss S, Avorn J. A review of uses of health care utilization databases for epidemiologic research on therapeutics. J Clin Epidemiol. 2005;58:323-37.

59. Brown JS, Holmes JH, Shah K, Hall K, Lazarus R, Platt R. Distributed health data networks: a practical and preferred approach to multi-institutional evaluations of comparative effectiveness, safety, and quality of care. Med Care. 2010;48(6 Suppl):S45-51.

60. Behrman RE, Benner JS, Brown JS, McClellan M, Woodcock J, Platt R. Developing the Sentinel System - a national resource for evidence development. N Engl J Med. 2011;364:498-9.

61. Southworth MR, Reichman ME, Unger EF. Dabigatran and postmarketing reports of bleeding. N Engl J Med. 2013;368: $1272-4$.

62. Trifiro G, Fourrier-Reglat A, Sturkenboom MC, Díaz Acedo C, Van Der Lei J; EU-ADR Group. The EU-ADR project: preliminary results and perspective. Stud Health Technol Inform. 2009;148:43-9.

63. Lawrenson R, Williams T, Farmer R. Clinical information for research; the use of general practice databases. J Public Health Med. 1999;21(3):299-304.

64. Ryan PB, Madigan D, Stang PE, Overhage JM, Racoosin JA, Hartzema AG. Empirical assessment of methods for risk identification in healthcare data: results from the experiments of the Observational Medical Outcomes Partnership. Stat Med. 2012;31(30):4401-15. doi:10.1002/sim.5620 (Epub 2012 Sep 27).

65. Alvarez Y, Hidalgo A, Maignen F, Slattery J. Validation of statistical signal detection procedures in EudraVigilance postauthorization data: a retrospective evaluation of the potential for earlier signalling. Drug Saf. 2010;33:475-87.

66. Lindquist $\mathrm{M}$. Use of triage strategies in the WHO signal-detection process. Drug Saf. 2007;30:635-7.

67. Harpaz R, DuMouchel W, LePendu P, Bauer-Mehren A, Ryan P, Shah NH. Performance of pharmacovigilance signal-detection algorithms for the FDA adverse event reporting system. Clin Pharmacol Ther. 2013;93:539-46.

68. Zhou X, Murugesan S, Bhullar H, Liu Q, Cai B, Wentworth C, Bate A. An evaluation of the THIN database in the OMOP Common Data Model for active drug safety surveillance. Drug Saf. 2013;36:119-34.

69. Adedeji AA, Sanusi B, Tella A, Akinsanya M, Ojo O, Akinwunmi MO, Tikare OA, Ogunwande IA, Ogundahunsi OA, Ayilara OO, Ademola TT, Fehintola FA, Ogundahunsi OA. Exposure to anti-malarial drugs and monitoring of adverse drug reactions using toll-free mobile phone calls in private retail sector in Sagamu, Nigeria: implications for pharmacovigilance. Malar J. 2011;9(10):230.

70. Aljadhey H, Alyabsi M, Alrwisan A, Alqahtani N, Almutairi R, Al Tawil E, Adam M, Shakir S, Aljeraisy M, Al-Blowi A, Alkhashan H, Albogami Y, Murray MD. The safety of H1N1 vaccine in children in Saudi Arabia: a cohort study using modern technology in a developing country. Drug Saf. 2012;35:555-61.

71. Kahn JG, Yang JS, Kahn JS. 'Mobile' health needs and opportunities in developing countries. Health Aff. 2010;29:252-8.

72. Olsson S, Pal SN, Stergachis A, Couper M. Pharmacovigilance activities in 55 low- and middle-income countries: a questionnaire-based analysis. Drug Saf. 2010;33:689-703.

73. Aagaard L, Strandell J, Melskens L, Petersen PSG, Hansen EH. Global patterns of adverse drug reactions over a decade: analyses of spontaneous reports to Vigibase $^{\mathrm{TM}}$. Drug Saf. 2012;35:1171-82.

74. Kuemmerle A, Dodoo ANO, Olsson S, Van Erp J, Burri C, Lalvani PS. Assessment of global reporting of adverse drug reactions for anti-malarials, including artemisinin-based combination therapy, to the WHO Programme for International Drug Monitoring. Malar J. 2011;10:57.

75. Bouvy JC, Ebbers HC, Schellekens H, Koopmanschap MA. The cost-effectiveness of periodic safety update reports for biologicals in Europe. Clin Pharmacol Ther. 2013;93:43342. 